\title{
Tracking of Dietary Intake and Diet Quality from Late Pregnancy to the Postpartum Period
}

\author{
Audrée Lebrun 1,2,3, Anne-Sophie Plante 2, Claudia Savard 1,2,3, Camille Dugas 1,2,3, \\ Bénédicte Fontaine-Bisson 4,5 , Simone Lemieux ${ }^{1,3} \mathbb{C D}$, Julie Robitaille ${ }^{1,2,3}$ (D) and \\ Anne-Sophie Morisset 1,2,3,*(D) \\ 1 School of Nutrition, Laval University, Québec City, QC G1V 0A6, Canada \\ 2 Endocrinology and Nephrology Unit, CHU de Québec-Université Laval Research Center, Québec City, \\ QC G1V 4G2, Canada \\ 3 Institute of Nutrition and Functional Foods (INAF), Laval University, Québec City, QC G1V 0A6, Canada \\ 4 School of Nutrition Sciences, University of Ottawa, Ottawa, ON K1N 6N5, Canada \\ 5 Institut du Savoir Montfort, Montfort Hospital, Ottawa, ON K1K 0T2, Canada \\ * Correspondence: anne-sophie.morisset@fsaa.ulaval.ca; Tel.: +1-418-656-2131 (ext. 413982)
}

Received: 19 July 2019; Accepted: 29 August 2019; Published: 3 September 2019

\begin{abstract}
The present study aimed to characterize dietary intake and diet quality from late pregnancy to six months postpartum. Participants $(n=28)$ completed $2-3 \mathrm{Web}$-based $24 \mathrm{~h}$ recalls at three distinct periods: (1) during the third trimester of pregnancy; (2) three months and (3) six months after delivery. Energy, macro-and micronutrient intakes (from foods and supplements), as well as the Canadian healthy eating index (C-HEI) were derived from the dietary recalls. No significant variation in energy and macronutrient intakes was observed between time points. The proportion of women taking at least one supplement decreased over time $(p=0.003)$. The total intake of several micronutrients (vitamins A, C, D, group B vitamins, iron, magnesium, zinc, calcium, phosphorus, manganese, and copper) decreased significantly over time ( $p<0.05$ for all micronutrients). The total C-HEI score and its components did not change, except for the total vegetables and fruit subscore, which decreased over time $(8.2 \pm 2.0$ in the $3 \mathrm{rd}$ trimester, $7.1 \pm 2.2$ at three months postpartum, $6.9 \pm 2.4$ at 6 months postpartum, $p=0.04)$. In conclusion, we observed a general stability in diet quality, energy, and macronutrient intakes from the third trimester of pregnancy to six months postpartum. However, several micronutrient intakes decreased over time, mostly due to changes in supplement use.
\end{abstract}

Keywords: pregnancy; postpartum; dietary intake; energy intake; supplements; dietary reference intakes (DRIs); diet quality; Healthy Eating Index

\section{Introduction}

Adopting healthy eating behaviors is crucial during pregnancy in order to positively influence both the mother's and the child's health [1-3]. Maintaining a balanced diet after childbirth is also important to ensure optimal maternal health, both in the short and long term [4-7]. In the short term, a woman's diet after delivery can influence weight retention since it is associated with the total energy intake [4]. In the long term, postpartum weight retention has been identified as a contributor to obesity, the latter being associated with an increase in morbidity and mortality risk [5,6]. Furthermore, adequate diet quality and dietary intake are essential to support the energy demand associated with lactation and ensure optimal early life nutrition for the newborn. In fact, greater maternal diet quality during pregnancy and lactation has been inversely associated with infant weight and adiposity in the early postpartum period, which could prevent obesity later in life [7]. Hence, it is important to maintain healthy eating behaviors both during and after pregnancy. 
However, few studies have investigated this continuum and the changes that can occur from pregnancy to the postpartum period. One study showed that Swedish women's diet quality tended to decrease after delivery, mostly due to an increased intake of discretionary food (e.g., sweets, cakes, cookies, crisps, and ice cream), and a decreased intake of vegetables and fruit [8]. Although a different study found a significant increase in the proportion of women engaging in more positive behaviors (drinking two or more cups of milk per day, consuming three or more servings of vegetables and fruit per day, and eating breakfast every day) from pre-pregnancy to pregnancy, that proportion decreased dramatically at six months postpartum [9]. It was also reported, in a cohort of low-income women with diverse ethnicity, that following childbirth, mean daily servings of grains, vegetables and fruit declined, while the percentage of energy from fat and added sugar increased in comparison with pregnancy [10]. Overall, although an improvement in diet quality has been reported during pregnancy $[9,11]$, healthy eating habits adopted in the prenatal period are not often maintained after childbirth [8-12].

Nevertheless, studies examining maternal diet from late pregnancy to the postpartum period rarely detail women's adherence to dietary recommendations [8-12], despite the significant impact of nutrition on maternal and child health. Thus, it appears relevant to examine women's diet during their transition to maternity as well as look at their adherence to nutritional recommendations. The aims of this study are to characterize dietary intake and diet quality from late pregnancy to the postpartum period and to investigate women's adherence to current Canadian nutritional recommendations at each time point. Firstly, we hypothesize that diet quality decreases from the third trimester to six months postpartum. Secondly, we hypothesize that adherence to micronutrient intake recommendations will be low in the postpartum period, especially for lactating women in whom nutritional needs are increased.

\section{Materials and Methods}

\subsection{Study Population}

The ANGE (Apports Nutritionnels durant la GrossessE) project included eighty-six (86) pregnant women recruited in Quebec City, QC, Canada. At the recruitment of the initial cohort, the exclusion criteria were to be under 18 years of age or to present a severe medical condition (i.e., type 1 or 2 diabetes, renal disease, inflammatory and autoimmune disorders). Previously published analyses included 79 women with complete nutritional data at each trimester of pregnancy $[13,14]$. In the present paper, the final sample includes 28 women for whom we have complete nutritional information for the 3rd trimester of pregnancy, as well as for the 3- and 6-months postpartum time points (see Figure 1). The Institutional Ethics Committee approved the project (Reference number: 2016-2866) and participants gave their informed written consent.

\subsection{The Automated Web-Based 24 h Recall (R24W)}

In the 3rd trimester of pregnancy (range: 31.9-36.1 gestational weeks, gestational age confirmed by ultrasound in the 1st trimester), at 3 months postpartum (range: 9.4-13.7 weeks after delivery) and 6 months postpartum (range: 23.0-26.4 weeks after delivery), participants used the R24W (Rappel de $24 \mathrm{~h} \mathrm{Web}$ ) platform. They completed, at each period, $2-3 \mathrm{Web}$-based $24 \mathrm{~h}$ dietary recalls. The average time between recalls was $1.0 \pm 0.5,1.4 \pm 0.9$ and $1.3 \pm 0.7$ weeks in the 3rd trimester, at 3 months postpartum, and at 6 months postpartum, respectively. The R24W has been previously described and was validated in pregnant women as well as in the general adult population [15-17]. Data regarding intake of total energy and 22 nutrients were analyzed.

\subsection{Healthy Eating Index}

The R24W platform automatically calculates the 2007 version of the Canadian Healthy Eating Index (C-HEI), an adaptation of the HEI developed by Kennedy et al. $[18,19]$ that was used to assess diet quality at each time point (3rd trimester, 3rd and 6th month of postpartum). The HEI has been 
validated in the general population and used by various authors to assess diet quality among pregnant women [18,20-22]. The assessment of the C-HEI relies on the number of servings reported by an individual, according to age and sex, as specified in the 2007 version of Canada's Food Guide [18,23]. In brief, the C-HEI is divided into eight adequacy components and three moderation components [18]. Based on the scoring criteria, participants were allocated a score between 0 and the potential maximum $(5,10$, or 20). In accordance with the method described earlier [18,23], scores are then added up for a maximum of 100 points, representing a perfect adherence to the 2007 version of Canada's Food Guide (see detailed method in Supplementary Table S1).

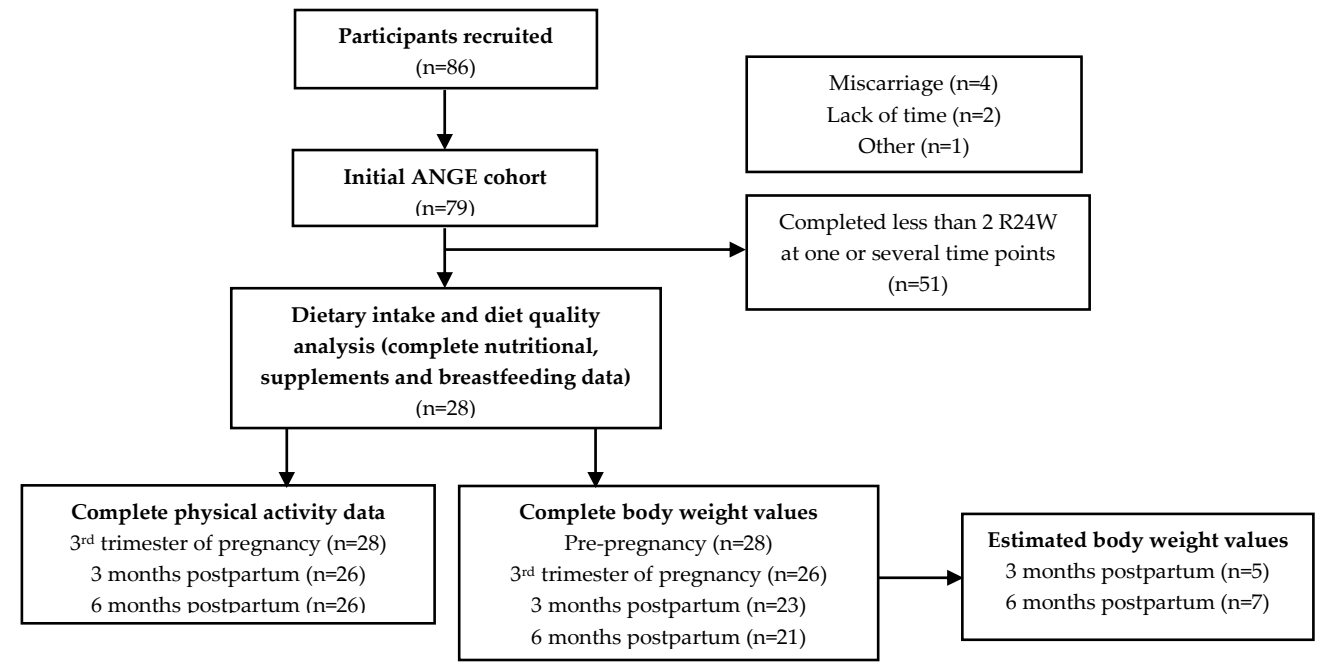

Figure 1. Flowchart of the study sample.

\subsection{Supplement Use}

All participants completed, at each time point, a Web questionnaire collecting information on supplement use. This questionnaire was previously described elsewhere [14]. In brief, for each supplement they reported taking, participants had to provide its name, its drug identification number, its measurement unit (e.g., tablet, drop, gram, milliliter, etc.) and its dose, as well as the frequency at which the reported dose was taken (e.g., once a day, twice a week, etc.). Nutritional data for all supplements were obtained by using the Health Canada Licensed Natural Health Product Database or the companies' product labels [24]. A research assistant reached out to participants when any supplement's characteristic was missing or incomplete. The use of supplements was compiled according to the supplement's type (multivitamin or one-nutrient supplement) and the number of women that reported taking each supplement.

\subsection{Other Web Questionnaires}

Women completed questionnaires on socioeconomic status and general health early in pregnancy to obtain data on sample descriptive characteristics. A Web-based self-administered questionnaire was completed by 27 women at 3 and 6 months postpartum to report the infant feeding methods and a research assistant contacted women with missing information.

\subsection{Estimated Energy and Protein Requirements}

Pre-pregnancy BMI was calculated using self-reported pre-pregnancy weight and measured height. The validated version of the pregnancy physical activity questionnaire (PPAQ) was completed by women as well as the International physical activity questionnaire (IPAQ) at 3 and 6 months postpartum [25-27]. Physical activity levels (PALs) were calculated with the total number of minutes per day participants engaged in moderate and high-intensity activities. Based on the dietary reference 
intakes (DRIs), we characterized participants as either sedentary, low-active, active or very active [28]. Estimated energy requirements (EERs) in the 3rd trimester were calculated with the participant's age, height, pre-pregnancy weight, physical activity level, to which $452 \mathrm{kcal}$ was added [28]. The weight of 26 women was measured during an on-site visit at the 3rd trimester of pregnancy. In the postpartum periods, a Web-based self-administered questionnaire regarding maternal weight was completed by 23 women at 3 months and by 21 women at 6 months. Mean weight difference between each period and pre-pregnancy was calculated (see Table 1). The difference between postpartum periods and pre-pregnancy weights can then be defined as weight retention. Since body weight values were missing for 5 women at 3 months postpartum and for 7 women at 6 months postpartum (see Figure 1), an estimation of their weight difference (in $\mathrm{kg}$ ) was made at those time points, in order to calculate their estimated energy and protein requirements. The estimated weight difference was calculated by using the mean weight difference (vs. pre-pregnancy weight) for the 23 women at 3 months $(4.3 \mathrm{~kg})$ and the mean weight difference for the 21 women at 6 months $(2.8 \mathrm{~kg})$. We were therefore able to calculate EERs at each postpartum period by using age, height, weight, physical activity levels and by adding $500 \mathrm{kcal}$ only for women who were breastfeeding at the time they completed the questionnaires [28]. In the 3rd trimester, daily estimated protein requirements (EPRs) were determined with the following calculation: $1.1 \mathrm{~g} / \mathrm{kg}$ of pre-pregnancy weight $+25 \mathrm{~g}$ of protein [28]. For postpartum periods, daily EPRs were estimated as $1.3 \mathrm{~g} / \mathrm{kg}$ of reported or estimated weight in breastfeeding mothers and $0.8 \mathrm{~g} / \mathrm{kg}$ for others [28].

Table 1. Participants' characteristics $(n=28)$.

\begin{tabular}{|c|c|}
\hline Variables & Mean \pm SD or $n(\%)$ \\
\hline Age at study enrollment (years) & $32.7 \pm 3.6$ \\
\hline Primiparous & $12(43)$ \\
\hline Pre-pregnancy BMI $\left(\mathrm{kg} / \mathrm{m}^{2}\right)$ & $24.9 \pm 5.1$ \\
\hline Normal weight & $18(64)$ \\
\hline Overweight & $6(21)$ \\
\hline Obese & $4(14)$ \\
\hline \multicolumn{2}{|l|}{ Weight (kg) } \\
\hline Pre-pregnancy & $69.3 \pm 16.6$ \\
\hline 3rd trimester of pregnancy (difference with pre-pregnancy) ${ }^{a}$ & $12.8 \pm 4.5$ \\
\hline 3 months postpartum (difference with pre-pregnancy) $b$ & $4.3 \pm 6.3$ \\
\hline 6 months postpartum (difference with pre-pregnancy) ${ }^{c}$ & $2.8 \pm 5.7$ \\
\hline Ethnicity-Caucasian & $28(100)$ \\
\hline \multicolumn{2}{|l|}{ Education } \\
\hline College & $2(7)$ \\
\hline University & $26(93)$ \\
\hline \multicolumn{2}{|l|}{ Household income } \\
\hline$<60,000 \$$ & $4(14)$ \\
\hline $60,000-79,999 \$$ & $5(18)$ \\
\hline $80,000-99,999 \$$ & $10(36)$ \\
\hline$>100,000 \$$ & $9(32)$ \\
\hline \multicolumn{2}{|l|}{ Breastfeeding (exclusively or not) } \\
\hline At 3 months postpartum & $27(96)$ \\
\hline At 6 months postpartum & $25(89)$ \\
\hline Duration of exclusive breastfeeding postpartum (months) ${ }^{\mathrm{C}}$ & $5.2 \pm 1.0$ \\
\hline
\end{tabular}

$$
{ }^{\mathrm{a}} n=26 ;{ }^{\mathrm{b}} n=23 ;{ }^{\mathrm{c}} n=21 \text {. }
$$




\subsection{Statistical Analyses}

Based on the automatically generated data from the completed dietary recalls, means and standard deviations were determined for energy, macro- and micronutrient intakes at each time point. Micronutrient intake from supplements and from food sources were compiled to estimate the total micronutrient intake. The intake of energy and nutrients were compared to their respective dietary reference intakes (DRIs). We then obtained a number of women that had intakes below the estimated average intakes (EARs) or above the upper intake limit (UL), when relevant [29]. A comparison was made between folate intake expressed as dietary folate equivalents (DFE) and the folate EAR. Comparison with the folic acid UL was only made with fortified foods and supplements because this limit is only applicable to synthetic forms of folic acid [28]. Similarly, only intake from supplements were compared to the UL for niacin and magnesium intakes [28]. The average energy intake (EI) and percentages of energy provided by each macronutrient (protein, carbohydrate, fats) were compared respectively with EERs and the acceptable ranges for each macronutrient [28]. The acceptable macronutrient distribution ranges (AMDR) are recommended intervals for energy proportion provided from each macronutrient, in order to ensure an adequate intake of essential nutrients [28]. Percentages of women with data below or above their EERs or AMDR were determined. Comparison of protein intake (g/day) with the EPRs was performed [28]. To assess changes in energy, macro- and micronutrient intakes and HEI scores from the 3rd trimester of pregnancy to 6 months postpartum, repeated measure analyses of variance (ANOVA) were computed. Tukey's honest significant difference post-hoc tests were then performed to identify specific differences between time points. Chi-square tests were conducted to compare supplement use (categorical variables) over time. All statistical analyses were performed with JMP version 14 (SAS Institute Inc., Cary, NC, USA).

\section{Results}

Participants' characteristics are presented in Table 1. All 28 included women were Caucasians and on average in their early thirties. The sample covered a wide range of pre-pregnancy BMI, but most of the participants had a normal weight. The majority was also multiparous and had a high level of education as well as a substantial household income. Most women breastfed, exclusively or not, up to six months after delivery. This sample's characteristics $(n=28)$ do not differ significantly from the ANGE project's original sample $(n=79)$ [13].

\subsection{Energy and Macronutrients}

Table 2 shows that no significant variation was observed for energy and macronutrient intakes across time points. Energy intake was below EER for $61 \%, 78 \%$ and $74 \%$ of the participants in the 3rd trimester of pregnancy, at three months and at six months postpartum, respectively. When macronutrient intake was examined in grams (Supplementary Table S2), protein intake of at least $64 \%$ of the participants exceeded the EPR at each period. However, at each time points, all women had protein intake as a percentage of energy within the AMDR. At each time point, more than $57 \%$ of women reported fat intake as percentages of energy intake that was above the AMDR. Inversely, carbohydrate intake as percentages of energy was below the AMDR range for up to $50 \%$ of participants. Dietary fiber intake decreased over time $(p=0.01)$ and more than $89 \%$ of participants had intake below the DRI at each period (Supplementary Table S2). No significant difference in energy and nutrient intakes was observed between normal weight, overweight or obese participants (data not shown). Secondary analyses were conducted to test associations between energy intake and weight retention (data not shown). No significant difference in weight retention was observed between participants who were below or over their EERs. However, Spearman's correlation showed that energy intake at six months after delivery was positively associated with postpartum weight retention at the same period $(\mathrm{r}=0.52, p=0.02)$. 
Table 2. Period-specific energy and macronutrient intakes as percentages of energy intake in comparison with dietary reference intakes.

\begin{tabular}{|c|c|c|c|c|c|c|c|c|c|c|}
\hline & \multicolumn{3}{|c|}{ 3rd Trimester of Pregnancy } & \multicolumn{3}{|c|}{3 Months Postpartum } & \multicolumn{3}{|c|}{6 Months Postpartum } & \multirow[b]{2}{*}{$\begin{array}{c}\text { Overall } \\
p \text {-Value }^{\mathrm{b}}\end{array}$} \\
\hline & Mean \pm SD & $\begin{array}{c}\text { \%Below } \\
\text { AMDR, } \\
\text { EER or UL }\end{array}$ & $\begin{array}{c}\text { \%Above } \\
\text { AMDR, } \\
\text { EER or UL }\end{array}$ & Mean \pm SD & $\begin{array}{c}\text { \%Below } \\
\text { AMDR, } \\
\text { EER or UL }\end{array}$ & $\begin{array}{c}\text { \%Above } \\
\text { AMDR, } \\
\text { EER or UL }\end{array}$ & Mean \pm SD & $\begin{array}{c}\text { \%Below } \\
\text { AMDR, } \\
\text { EER or UL }\end{array}$ & $\begin{array}{c}\text { \%Above } \\
\text { AMDR, } \\
\text { EER or UL }\end{array}$ & \\
\hline $\operatorname{EER}(\mathrm{kcal} / \text { day })^{\mathrm{a}}$ & $2497 \pm 203$ & - & - & $2578 \pm 201$ & - & - & $2678 \pm 327$ & - & - & - \\
\hline Energy intake (kcal/day) & $2321 \pm 429$ & 61 & 39 & $2305 \pm 506$ & 78 & 22 & $2227 \pm 474$ & 74 & 26 & 0.48 \\
\hline AMDR protein, E\% & $10-35$ & - & - & $10-35$ & - & - & $10-35$ & - & - & - \\
\hline Protein, E\% & $17.5 \pm 2.8$ & 0 & 0 & $17.1 \pm 2.8$ & 0 & 0 & $16.9 \pm 3.2$ & 0 & 0 & 0.70 \\
\hline AMDR carbohydrate, E\% & $45-65$ & - & - & $45-65$ & - & - & $45-65$ & - & - & - \\
\hline Carbohydrate, E\% & $47.0 \pm 5.9$ & 29 & 0 & $44.8 \pm 6.1$ & 46 & 0 & $45.3 \pm 5.9$ & 50 & 0 & 0.08 \\
\hline UL added sugar, E\% & 25 & - & - & 25 & - & - & 25 & - & - & - \\
\hline Added sugar, E\% & $9.8 \pm 3.8$ & 100 & 0 & $9.4 \pm 4.0$ & 96 & 0 & $9.1 \pm 3.2$ & 100 & 0 & 0.71 \\
\hline AMDR, total fat, E\% & $20-35$ & - & - & $20-35$ & - & - & $20-35$ & - & - & - \\
\hline Total fat, E\% & $35.5 \pm 5.0$ & 0 & 57 & $36.6 \pm 4.6$ & 0 & 64 & $36.3 \pm 4.7$ & 0 & 64 & 0.57 \\
\hline SFA, E\% & $13.6 \pm 2.1$ & - & - & $12.9 \pm 1.6$ & - & - & $13.0 \pm 2.7$ & - & - & 0.32 \\
\hline MUFA \% & $12.4 \pm 2.2$ & - & - & $13.0 \pm 2.1$ & - & - & $13.0 \pm 2.1$ & - & - & 0.30 \\
\hline PUFA\% & $6.7 \pm 2.1$ & - & - & $7.8 \pm 2.8$ & - & - & $7.4 \pm 1.8$ & - & - & 0.08 \\
\hline
\end{tabular}

a $n=27$ for 3 and 6 months post-natal; ${ }^{\mathrm{b}} p$-value for repeated measures ANOVA performed to assess variations in energy and macronutrient intakes across periods. When no dietary reference intake is established for a nutrient, the - is used instead of a 0. AMDR: acceptable macronutrient distribution range; EER: estimated energy requirements, calculated with the following formula: $354-(6.91 \times$ age $)+$ physical activity coefficient $\times[(9.36 \times$ weight $)+(726 \times$ height $)]$, to which an additional $452 \mathrm{kcal}$ were added in the 3 rd timester or an additional 500 kcal were added in the postpartum period if the participant was breastfeeding; UL: upper limit of $25 \%$ of the energy provided by added sugar according to the dietary reference intakes. SFA: saturated fatty acids; MUFA: monounsaturated fatty acids; PUFA: polyunsaturated fatty acids. 


\subsection{Vitamins and Minerals}

Micronutrient intake derived from the R24W (food sources only) and proportions of women that reported intake above or below the corresponding DRIs are presented in Table 3. Micronutrient intake from food alone decreased from late pregnancy to six months postpartum for vitamins $\mathrm{A}$ and $\mathrm{C}$ as well as thiamin, riboflavin, calcium, and phosphorus ( $p \leq 0.03$ for all micronutrients). A downward trend was observed for vitamin $\mathrm{D}$, vitamin $\mathrm{B}_{12}$, and iron intakes. As presented in Table 4 , fewer women reported the use of supplements after delivery $(89 \%, 68 \%$ and $46 \%$ at the $3 \mathrm{rd}$ trimester of pregnancy, at three and six months postpartum, respectively, $p=0.003$ ), and multivitamins remained the most commonly used supplement. A secondary analysis showed that $67 \%$ and $52 \%$ of participants who breastfed were taking at least one supplement at three and six months after delivery, respectively. As shown in Table 5, when food sources and dietary supplements were combined, total micronutrient intake decreased from late pregnancy to the postpartum period for vitamins $A, B_{6}, B_{12}, C$ and D as well as for thiamin, riboflavin, niacin, pantothenic acid, iron, magnesium, zinc, calcium, phosphorus, manganese and copper ( $p \leq 0.03$ for all micronutrients). At each period, a higher proportion of women had a total micronutrient intake below the EAR, particularly for vitamins A $(4 \%, 54 \%, 54 \%)$ and D $(11 \%, 36 \%, 57 \%)$. Total intake of sodium was above the UL for more than $79 \%$ of women at each time point. Similar results regarding the total micronutrient intake as well as EAR and UL adherence were observed, both at three and six months postpartum, when looking only at lactating women, which represents $89 \%-96 \%$ of our sample.

\subsection{Diet Quality}

Mean HEI scores are presented in Table 6. Total and sub-scores did not significantly vary from late pregnancy to six months postpartum, except for the total vegetables and fruit sub-score, which decreased over time $(p=0.04)$ and more specifically between the third trimester of pregnancy and six months postpartum $(p=0.03)$. 
Table 3. Period-specific micronutrient intake from food alone in comparison with dietary reference intakes.

\begin{tabular}{|c|c|c|c|c|c|c|c|c|c|c|}
\hline & \multicolumn{3}{|c|}{ 3rd Trimester of Pregnancy } & \multicolumn{3}{|c|}{3 Months Postpartum } & \multicolumn{3}{|c|}{6 Months Postpartum } & \multirow[b]{2}{*}{$\begin{array}{c}\text { Overall } \\
p \text {-Value }\end{array}$} \\
\hline & Mean \pm SD & $\begin{array}{c}\text { \%Below } \\
\text { EAR }\end{array}$ & \%Above UL & Mean \pm SD & $\begin{array}{c}\text { \%Below } \\
\text { EAR }\end{array}$ & \%Above UL & Mean \pm SD & $\begin{array}{c}\text { \%Below } \\
\text { EAR }\end{array}$ & \%Above UL & \\
\hline Vitamin D IU/day & $292 \pm 128$ & 75 & 0 & $252 \pm 116$ & 86 & 0 & $236 \pm 105$ & 93 & 0 & 0.06 \\
\hline Iron, mg/day & $14.8 \pm 3.7$ & 96 & 0 & $14.9 \pm 3.3$ & 0 & 0 & $14.0 \pm 3.5$ & 0 & 0 & 0.09 \\
\hline Folate, $\mu \mathrm{g}$ DFE/day & $518 \pm 151$ & 57 & - & $519 \pm 130$ & 36 & - & $474 \pm 125$ & 43 & - & 0.11 \\
\hline Folic acid, $\mu \mathrm{g} /$ day & $136 \pm 75$ & - & 0 & $151 \pm 67$ & - & 0 & $134 \pm 66$ & - & 0 & 0.28 \\
\hline Vitamin $B_{6}, \mathrm{mg} /$ day & $1.8 \pm 0.4$ & 32 & 0 & $1.8 \pm 0.1$ & 36 & 0 & $1.7 \pm 0.4$ & 50 & 0 & 0.13 \\
\hline Magnesium, mg/day & $424 \pm 79$ & 4 & - & $399 \pm 99$ & 7 & - & $400 \pm 100$ & 11 & - & 0.12 \\
\hline Vitamin A, $\mu$ RAE/day & $975 \pm 371$ & 7 & 0 & $817 \pm 317$ & 68 & 0 & $752 \pm 334$ & 71 & 0 & 0.005 \\
\hline Zinc, $\mathrm{mg} /$ day & $13.8 \pm 3.9$ & 7 & 0 & $12.2 \pm 3.6$ & 32 & 0 & $12.4 \pm 3.9$ & 36 & 0 & 0.06 \\
\hline Calcium, mg/day & $1560 \pm 453$ & 0 & 0 & $1252 \pm 386$ & 18 & 0 & $1217 \pm 377$ & 18 & 0 & 0.002 \\
\hline Vitamin $C, \mathrm{mg} /$ day & $148 \pm 73$ & 11 & 0 & $109 \pm 58$ & 25 & 0 & $108 \pm 53$ & 43 & 0 & 0.03 \\
\hline Thiamin, mg/day & $1.8 \pm 0.5$ & 4 & - & $1.8 \pm 0.6$ & 7 & - & $1.7 \pm 0.5$ & 14 & - & 0.01 \\
\hline Vitamin $B_{12}, \mu g /$ day & $5.8 \pm 2.6$ & 0 & - & $4.8 \pm 1.7$ & 7 & - & $4.7 \pm 1.7$ & 11 & - & 0.09 \\
\hline Riboflavin, mg/day & $2.7 \pm 0.7$ & 0 & - & $2.4 \pm 0.5$ & 0 & - & $2.3 \pm 0.6$ & 7 & - & 0.004 \\
\hline Niacin, mg NE/day & $46.1 \pm 9.0$ & 0 & - & $47.0 \pm 9.4$ & 0 & - & $45.9 \pm 11.3$ & 0 & - & 0.70 \\
\hline Pantothenic acid, mg/day & $6.9 \pm 1.6$ & - & - & $6.4 \pm 1.5$ & - & - & $6.4 \pm 1.6$ & - & - & 0.18 \\
\hline Phosphorus, mg/day & $1768 \pm 362$ & 0 & 0 & $1614 \pm 346$ & 0 & 0 & $1549 \pm 354$ & 0 & 0 & 0.01 \\
\hline Sodium, $\mathrm{mg} /$ day & $3303 \pm 893$ & - & 86 & $3229 \pm 921$ & - & 86 & $3236 \pm 1107$ & - & 79 & 0.93 \\
\hline Manganese, mg/day & $4.3 \pm 1.3$ & - & 0 & $4.1 \pm 1.2$ & - & 0 & $3.9 \pm 1.2$ & - & 0 & 0.17 \\
\hline Selenium, $\mu \mathrm{g} / \mathrm{day}$ & $136 \pm 27$ & 0 & 0 & $137 \pm 34$ & 0 & 0 & $136 \pm 49$ & 0 & 0 & 0.99 \\
\hline Copper, mg/day & $1.6 \pm 0.3$ & 0 & 0 & $1.5 \pm 0.3$ & 4 & 0 & $1.5 \pm 0.8$ & 4 & 0 & 0.50 \\
\hline
\end{tabular}

a p-value for repeated measures ANOVA performed to assess variations in micronutrient intake across periods. When no EAR or UL was established for a nutrient, the "-" is used instead of a 0. EAR: estimated average requirements; UL: upper intake limit; DFE: dietary folate equivalent; RAE: retinol activity equivalents; NE: niacin equivalent. 
Table 4. Proportions of vitamin- and mineral-supplement users among participants.

\begin{tabular}{|c|c|c|c|c|}
\hline & \multicolumn{3}{|c|}{ n $(\%)$} & \multirow[b]{2}{*}{ Overall $p$-Value } \\
\hline & 3rd Trimester of Pregnancy & 3 Months Postpartum & 6 Months Postpartum & \\
\hline$\geq 1$ supplement (all types) & $25(89)$ & $19(68)$ & $13(46)$ & 0.003 \\
\hline \multicolumn{5}{|c|}{ Number of supplements (all types) taken during each period } \\
\hline 0 & $3(11)$ & $9(32)$ & $15(54)$ & 0.003 \\
\hline 1 & $21(75)$ & $14(50)$ & $11(39)$ & 0.03 \\
\hline$\geq 2$ & $4(14)$ & $5(18)$ & $2(7)$ & 0.69 \\
\hline \multicolumn{5}{|c|}{ Types of supplements most commonly taken } \\
\hline Multivitamins & $23(92)$ & $16(84)$ & $12(92)$ & 0.01 \\
\hline Folic acid supplement & $2(8)$ & $1(5)$ & $1(8)$ & 0.77 \\
\hline Vitamin D supplement & $2(8)$ & $2(11)$ & $1(8)$ & 0.81 \\
\hline Iron supplement & $1(4)$ & $1(5)$ & $0(0)$ & 0.60 \\
\hline Omega-3 supplement (mostly EPA-DHA) & $1(4)$ & $1(5)$ & $1(8)$ & 1.00 \\
\hline
\end{tabular}

a $p$-value for chi-square tests performed to assess variations in supplement use across periods. 
Table 5. Period-specific total micronutrient intake (including food sources and supplements) in comparison with dietary reference intakes.

\begin{tabular}{|c|c|c|c|c|c|c|c|c|c|c|}
\hline & \multicolumn{3}{|c|}{ 3rd Trimester of Pregnancy } & \multicolumn{3}{|c|}{3 Months Postpartum } & \multicolumn{3}{|c|}{6 Months Postpartum } & \multirow[b]{2}{*}{$\begin{array}{c}\text { Overall } \\
p \text {-Value }\end{array}$} \\
\hline & Mean \pm SD & $\begin{array}{l}\text { \%Below } \\
\text { EAR }\end{array}$ & \%Above UL & Mean \pm SD & $\begin{array}{c}\text { \%Below } \\
\text { EAR }\end{array}$ & \%Above UL & Mean \pm SD & $\begin{array}{c}\text { \%Below } \\
\text { EAR }\end{array}$ & \%Above UL & \\
\hline Vitamin D IU/day & $841 \pm 776$ & 11 & 4 & $684 \pm 848$ & 36 & 4 & $586 \pm 846$ & 57 & 4 & 0.001 \\
\hline Iron, mg/day & $45.5 \pm 32.7$ & 18 & 39 & $33.8 \pm 18.5$ & 0 & 25 & $26.7 \pm 15.7$ & 0 & 14 & 0.03 \\
\hline Folate, $\mu \mathrm{g}$ DFE/day & $1175 \pm 993$ & 18 & - & $1608 \pm 2039$ & 18 & - & $1095 \pm 1045$ & 21 & - & 0.30 \\
\hline Folic acid, $\mu \mathrm{g} /$ day & $793 \pm 999$ & - & 46 & $1240 \pm 1991$ & - & 61 & $755 \pm 1023$ & - & 46 & 0.29 \\
\hline Vitamin $B_{6}, \mathrm{mg} /$ day & $6.1 \pm 4.2$ & 4 & 0 & $14.1 \pm 46.9$ & 14 & 4 & $3.8 \pm 3.7$ & 32 & 0 & 0.01 \\
\hline Magnesium, mg/day & $474 \pm 81$ & 0 & 0 & $429 \pm 106$ & 7 & 0 & $420 \pm 106$ & 11 & 0 & 0.01 \\
\hline Vitamin A, $\mu \mathrm{g}$ RAE/day & $1473 \pm 607$ & 4 & 0 & $924 \pm 356$ & 54 & 0 & $838 \pm 360$ & 54 & 0 & $<0.0001$ \\
\hline Calcium, mg/day & $1779 \pm 471$ & 0 & 4 & $1415 \pm 387$ & 11 & 0 & $1330 \pm 433$ & 14 & 0 & $<0.0001$ \\
\hline Vitamin C, mg/day & $229 \pm 70$ & 4 & 0 & $171 \pm 86$ & 25 & 0 & $151 \pm 78$ & 25 & 0 & 0.001 \\
\hline Thiamin, mg/day & $3.5 \pm 1.1$ & 0 & - & $3.2 \pm 1.6$ & 0 & - & $2.5 \pm 1.2$ & 7 & - & 0.001 \\
\hline Vitamin $B_{12}, \mu \mathrm{g} /$ day & $11.2 \pm 5.7$ & 0 & - & $8.8 \pm 6.1$ & 4 & - & $7.2 \pm 4.6$ & 7 & - & 0.002 \\
\hline Riboflavin, mg/day & $4.5 \pm 1.5$ & 0 & - & $3.8 \pm 1.6$ & 0 & - & $3.2 \pm 1.4$ & 4 & - & 0.0002 \\
\hline Niacin, mg NE/day & $61.7 \pm 12.2$ & 0 & 0 & $58.1 \pm 15.2$ & 0 & 4 & $53.4 \pm 15.8$ & 0 & 0 & 0.01 \\
\hline Pantothenic acid, mg/day & $11.6 \pm 2.9$ & - & - & $9.9 \pm 3.4$ & - & - & $8.9 \pm 3.6$ & - & - & 0.001 \\
\hline Phosphorus, mg/day & $1177 \pm 349$ & 0 & 0 & $1614 \pm 346$ & 0 & 0 & $1549 \pm 354$ & 0 & 0 & 0.01 \\
\hline Sodium, mg/day & $3303 \pm 893$ & - & 86 & $3229 \pm 921$ & - & 86 & $3236 \pm 1107$ & - & 79 & 0.93 \\
\hline Manganese, mg/day & $5.4 \pm 1.2$ & - & 0 & $4.8 \pm 1.4$ & - & 0 & $4.5 \pm 1.1$ & - & 0 & 0.002 \\
\hline Copper, mg/day & $2.8 \pm 0.9$ & 0 & 0 & $2.3 \pm 1.1$ & 4 & 0 & $2.1 \pm 1.1$ & 4 & 0 & 0.02 \\
\hline
\end{tabular}

of a 0. EAR: estimated average requirements; UL: upper intake limit; DFE: dietary folate equivalent; RAE: retinol activity equivalents; NE: niacin equivalent. 
Table 6. Healthy Eating Index total and subscores from late pregnancy to postpartum.

\begin{tabular}{cccccc}
\hline HEI & $\begin{array}{c}\text { Score } \\
\text { Range }\end{array}$ & $\begin{array}{c}\text { 3rd } \\
\text { Trimester }\end{array}$ & $\begin{array}{c}\text { 3 Months } \\
\text { Postpartum }\end{array}$ & $\begin{array}{c}\text { 6 Months } \\
\text { Postpartum }\end{array}$ & $\begin{array}{c}\text { Overall } \\
\text {-Value }^{\mathbf{a}}\end{array}$ \\
\hline Total & $0-100$ & $64.1 \pm 12.2$ & $61.2 \pm 11.4$ & $60.5 \pm 8.3$ & 0.13 \\
Adequacy & $0-60$ & $46.4 \pm 7.6$ & $44.5 \pm 8.3$ & $43.3 \pm 7.5$ & 0.08 \\
Total vegetables and fruit & $0-10$ & $8.2 \pm 2.0$ & $7.1 \pm 2.2$ & $6.9 \pm 2.4$ & 0.04 \\
Whole fruit & $0-5$ & $4.4 \pm 1.5$ & $3.6 \pm 1.9$ & $3.4 \pm 1.7$ & 0.09 \\
Dark green and orange & $0-5$ & $3.3 \pm 1.6$ & $3.4 \pm 1.5$ & $2.9 \pm 1.6$ & 0.25 \\
vegetables & $0-5$ & $4.4 \pm 0.7$ & $4.5 \pm 0.8$ & $4.2 \pm 1.0$ & 0.29 \\
Total grains products & $0-5$ & $2.6 \pm 1.8$ & $2.7 \pm 1.7$ & $2.3 \pm 1.9$ & 0.62 \\
Whole grains & $0-10$ & $9.5 \pm 1.4$ & $8.8 \pm 1.9$ & $8.8 \pm 2.4$ & 0.08 \\
Milk and alternatives & $0-10$ & $8.9 \pm 1.6$ & $8.6 \pm 2.0$ & $8.5 \pm 1.9$ & 0.16 \\
Meat and alternatives & $0-10$ & $5.2 \pm 3.7$ & $5.8 \pm 3.7$ & $6.4 \pm 3.3$ & 0.29 \\
Unsaturated fat & $0-40$ & $17.7 \pm 7.2$ & $16.7 \pm 6.7$ & $17.2 \pm 7.6$ & 0.65 \\
Moderation & $0-10$ & $2.8 \pm 2.6$ & $3.5 \pm 2.4$ & $3.7 \pm 3.1$ & 0.33 \\
Saturated fats & $0-10$ & $4.6 \pm 2.8$ & $4.8 \pm 2.9$ & $4.8 \pm 3.2$ & 0.93 \\
Sodium & $0-20$ & $10.3 \pm 5.1$ & $8.4 \pm 5.2$ & $8.7 \pm 4.8$ & 0.16 \\
Other foods &
\end{tabular}

a $p$-value for repeated measures ANOVA performed to assess variations in HEI-scores across periods.

\section{Discussion}

Our prospective evaluation of women's dietary intake revealed stability in energy and macronutrient intakes from late pregnancy to six months postpartum. Most women were below their energy estimated requirements and above their protein estimated requirements. Total micronutrient intake decreased from late pregnancy to six months after delivery for many vitamins and minerals. We also observed a decrease in diet quality regarding the total consumption of vegetables and fruit.

Stability in energy intake was found from late pregnancy to six months after delivery. Likewise, Talai Rad et al., as well as Moran et al. found no significant variation in women's energy intake from pregnancy to the postpartum period [20,30]. In contrast, George et al. found that the transition from pregnancy to the postpartum period was associated with a decrease in the mean energy intake in the overall sample, and in both lactating and nonlactating low-income women [10]. However, our small study sample consisted mostly of lactating women, for whom the energy estimated requirements were similar from late pregnancy to the postpartum period, which may explain the stability in energy intake. We also found that most women were under their respective EERs in the third trimester of pregnancy as well as in the postpartum period. In contrast, Moran et al. found that most of 301 overweight or obese women met the Australian Nutrient Reference Values in energy from pregnancy to four months postpartum [20]. In comparison with our participants, women in this study were all overweight or obese and came from an area of greater social deprivation [20]. Also, at four months after delivery, $57 \%$ of Australian women were breastfeeding versus $96 \%$ of our participants at three months postpartum [20]. Considering that breastfeeding requires additional energy intake, we suggest that lactating mothers encounter more difficulties in meeting these caloric recommendations. The underreporting of energy intake may also have influenced mean caloric intake of our study sample considering that other studies have reported divergent percentages (between 13\% and 49\%) of under-reporters during pregnancy [31-34]. However, there is a lack of consistency in the methods and thresholds used to evaluate the misreporting of energy intake in pregnancy, indicating a need to further investigate which method would be the most appropriate to use.

Regarding macronutrient intake, most of our participants had protein intake (as percentages of energy intake) within their respective acceptable distribution ranges, at all time points. However, the majority of our participants had protein intake that exceeded their EPRs at all periods, similarly to Moran et al. [20]. Further, up to $50 \%$ of women had carbohydrate consumption (as a percentage of energy intake) below the AMDR, with a higher proportion in the postpartum period compared to 
what has been observed in overall pregnancy [14]. Furthermore, many participants had fat intake as a percentage of energy intake that was above the acceptable distribution range from late pregnancy to six months after delivery. Similarly, Talai Rad et al. found that in 32 healthy women, the proportion of fat intake within the total caloric intake (36\%) slightly exceeded the German Nutrition Society recommendation from early pregnancy to six weeks after delivery [30]. Additionally, a previous analysis in this cohort found that macronutrient intake, as percentages of energy intake, was stable throughout pregnancy [14]. Hence, the mean intake of macronutrients, in comparison with acceptable distribution ranges, does not seem to change from early pregnancy to six months after delivery in our cohort of high-income women. Finally, we observed that almost all women did not meet the adequate intake recommended for dietary fiber, at each period, similarly to the results obtained during pregnancy in the initial ANGE cohort [14] and in the general population [35]. Also, fiber intake decreased from late pregnancy to six months after delivery, in contrast to Moran et al. who found a stability from pregnancy to four months postpartum [20].

Despite our small sample size, we found that total intake of 16 of the 20 vitamins and minerals had significantly decreased from the third trimester of pregnancy to six months postpartum, which is concordant with the decrease in vegetables and fruit intakes observed with the HEI-score. In addition, most participants did not meet the recommendation for vitamin $\mathrm{A}$ in the postpartum period since the EAR for this vitamin almost doubles in the context of lactation compared to pregnancy [29]. Also, a significant proportion of women failed to meet the recommendation for vitamin $\mathrm{D}$ after delivery. A decreasing trend observed for the milk and alternatives HEI subscore may partially explain the observed decrease in vitamin D since most of these foods are fortified with vitamin D. Nevertheless, and more importantly, the decrease in micronutrient intake might be explained by the decline in supplement use following the delivery, despite the Society of Obstetricians and Gynaecologists of Canada's recommendation for women to keep taking a prenatal multivitamin as long as breastfeeding continues [36]. Similar results regarding total micronutrient intake and adherence to recommendations were observed in the postpartum period when looking only at lactating women, which represent most of our sample. A decrease in total micronutrient intake of breastfeeding participants persisted even if more than half of them continued taking at least one supplement after delivery. Moran et al. also found lower total intake of iron, zinc and calcium as well as vitamins $\mathrm{A}, \mathrm{B}_{6}$ and $\mathrm{C}$ from the third trimester to four months postpartum, with a significant decrease in supplement use over this period [20]. It would therefore appear that women reduced their supplement use after childbirth, which may put lactating women at risk of non-adherence to micronutrient recommendations, since their nutritional needs are increased compared to non-lactating women.

Diet quality remained stable from late pregnancy to the postpartum period in this limited sample size, except for the total vegetables and fruit sub-score. Total C-HEI score and its components are based on the number of servings consumed, therefore participants seemed to decrease their vegetable and fruit intakes after delivery in comparison to late pregnancy. This might have had an impact on the observed decrease in dietary intake of fiber, vitamin A, and vitamin C. As previously published by our research team (initial ANGE cohort), total C-HEI scores did not significantly vary throughout pregnancy [13]. However, the adequacy sub-score decreased significantly from early to late pregnancy, mostly due to a decreased intake in vegetables and fruit [13]. We can hypothesize that vegetables and fruit intakes decrease throughout pregnancy, which continues in the postpartum period, as reported in other studies [8-10]. This is concordant with the supposition that motivation for healthy eating might decrease as pregnancy progresses and after delivery. Interestingly, a study found that multiparous women, who make up the majority of this sample, have lower intentions to eat in a healthier manner compared to new and non-parents [37]. The same authors hypothesized that mothers may find it difficult to put time and energy in preparing healthy meals for multiple children, thus leading to the subsequent decrease in motivation for their own dietary behaviors [37]. As a possible strategy to counter the decrease in micronutrient intake and diet quality, healthcare providers should reinforce 
recommendations regarding multivitamin supplementation and address the importance of vegetables and fruit consumption during postpartum follow-ups.

To our knowledge, this is the first study to prospectively assess whether women adhere or not to current Canadian nutritional recommendations up to six months after delivery. A major strength of this study is the use of detailed information collected on dietary intake with the completion of 2-3 validated Web-based $24 \mathrm{~h}$ recalls at each period combined with a Web questionnaire on supplements use. However, some limitations need to be acknowledged, mainly regarding the small sample size and lack of representativeness of our sample. The small sample size could have attenuated the statistical significance, however, the results we observed were similar to those from other studies in larger cohorts. Our sample can also include a potential proportion of under-reporters and a possible overestimation of the energy requirement of overweight or obese breastfeeding women [38], which would have inflated the proportion of women not meeting their EERs. Since all women were Caucasian and most of them were of higher socioeconomic status, our results may not be representative of mothers from a more ethnically and socioeconomically diverse population. Diet quality and dietary intake should be further investigated in a larger and more representative cohort, from pregnancy to the postpartum period.

\section{Conclusions}

In summary, we observed relative stability in diet quality, energy and macronutrient intakes from late pregnancy to the postpartum period, but intake of several micronutrients decreased from the third trimester of pregnancy to six months after delivery. Decreased use of supplements, energy intake below the estimated requirements, lower intake of vegetables and fruit as well as increased micronutrient needs may put lactating women at risk of nutritional deficiencies. However, further research is needed, first, to confirm in a larger and more diverse cohort the decrease we observed in micronutrient intake, as well as in vegetables and fruit consumption from pregnancy to the postpartum period, and second, to identify women at a higher risk of inadequate postpartum diet that could be targeted in future interventions.

Supplementary Materials: The following are available online at http://www.mdpi.com/2072-6643/11/9/2080/s1, Table S1: Components of Canadian adaptation of Healthy Eating Index, range of scores and scoring criteria, Table S2: Period-specific macronutrient intake in comparison with dietary reference intakes.

Author Contributions: All listed authors contributed substantially to the conception and design process that led to the first draft of this manuscript. They all revised a first draft of the manuscript and provided their input. A.L. collected the data under the supervision of A.-S.M. and conducted primary statistical analyses of the data with the help of A.-S.P., C.S., C.D., B.F.-B., S.L., J.R. and A.-S.M. All authors participated in the secondary analyses and interpretation of data. All authors gave their approval of the manuscript's final version to be published and therefore take public responsibility for the content of the manuscript. Finally, all authors agreed to be accountable for all aspects of the work.

Funding: The Danone Institute of Canada and startup founds (Fonds de recherche du Québec-Santé et Fondation du CHU de Québec) funded this project. All funding permitted the collection, analysis, and interpretation of data, but played no role in the writing of this manuscript.

Acknowledgments: We would like to acknowledge the valuable collaboration of the research team that developed the R24W in collaboration with S.L. and J.R.: Benoit Lamarche, Louise Corneau, Catherine Laramée, and Simon Jacques. We would also like to acknowledge Elizabeth Izedonmven, undergraduate student, for the revision of this manuscript.

Conflicts of Interest: The authors declare no conflict of interest.

\section{References}

1. Kaiser, L.; Allen, L.H. Position of the American Dietetic Association: Nutrition and lifestyle for a healthy pregnancy outcome. J. Am. Diet. Assoc. 2008, 108, 553-561. [PubMed]

2. Symonds, M.E.R. Maternal-Fetal Nutrition during Pregnancy and Lactation; Cambridge University Press: Cambridge, UK, 2010.

3. Rolfes, S.R.; Pinna, K.; Whitney, E. Understanding Normal and Clinical Nutrition; Wadsworth Publishing Company, Inc.: Belmont, CA, USA, 2002. 
4. Boghossian, N.S.; Yeung, E.H.; Lipsky, L.M.; Poon, A.K.; Albert, P.S. Dietary patterns in association with postpartum weight retention. Am. J. Clin. Nutr. 2013, 97, 1338-1345. [CrossRef] [PubMed]

5. Flegal, K.M.; Graubard, B.I.; Williamson, D.F.; Gail, M.H. Cause-specific excess deaths associated with underweight, overweight, and obesity. JAMA 2007, 298, 2028-2037. [CrossRef] [PubMed]

6. Rong, K.; Yu, K.; Han, X.; Szeto, I.M.; Qin, X.; Wang, J.; Ning, Y.; Wang, P.; Ma, D. Pre-pregnancy BMI, gestational weight gain and postpartum weight retention: A meta-analysis of observational studies. Public Health Nutr. 2015, 18, 2172-2182. [CrossRef] [PubMed]

7. Tahir, M.J.; Haapala, J.L.; Foster, L.P.; Duncan, K.M.; Teague, A.M.; Kharbanda, E.O.; McGovern, P.M.; Whitaker, K.M.; Rasmussen, K.M.; Fields, D.A.; et al. Higher Maternal Diet Quality during Pregnancy and Lactation Is Associated with Lower Infant Weight-For-Length, Body Fat Percent, and Fat Mass in Early Postnatal Life. Nutrients 2019, 11. [CrossRef] [PubMed]

8. Wennberg, A.L.; Isaksson, U.; Sandstrom, H.; Lundqvist, A.; Hornell, A.; Hamberg, K. Swedish women's food habits during pregnancy up to six months post-partum: A longitudinal study. Sex. Reprod. Healthc. 2016, 8, 31-36. [CrossRef] [PubMed]

9. Olson, C.M. Tracking of food choices across the transition to motherhood. J. Nutr. Educ. Behav. 2005, 37, 129-136. [CrossRef]

10. George, G.C.; Hanss-Nuss, H.; Milani, T.J.; Freeland-Graves, J.H. Food choices of low-income women during pregnancy and postpartum. J. Am. Diet. Assoc. 2005, 105, 899-907. [CrossRef]

11. Wiltheiss, G.A.; Lovelady, C.A.; West, D.G.; Brouwer, R.J.; Krause, K.M.; Ostbye, T. Diet quality and weight change among overweight and obese postpartum women enrolled in a behavioral intervention program. J. Acad. Nutr. Diet. 2013, 113, 54-62. [CrossRef]

12. George, G.C.; Milani, T.J.; Hanss-Nuss, H.; Freeland-Graves, J.H. Compliance with dietary guidelines and relationship to psychosocial factors in low-income women in late postpartum. J. Am. Diet. Assoc. 2005, 105, 916-926. [CrossRef]

13. Savard, C.; Lemieux, S.; Carbonneau, E.; Provencher, V.; Gagnon, C.; Robitaille, J.; Morisset, A.S. TrimesterSpecific Assessment of Diet Quality in a Sample of Canadian Pregnant Women. Int. J. Environ. Res. Public Health 2019, 16. [CrossRef] [PubMed]

14. Savard, C.; Lemieux, S.; Weisnagel, S.J.; Fontaine-Bisson, B.; Gagnon, C.; Robitaille, J.; Morisset, A.S. TrimesterSpecific Dietary Intakes in a Sample of French-Canadian Pregnant Women in Comparison with National Nutritional Guidelines. Nutrients 2018, 10. [CrossRef] [PubMed]

15. Jacques, S.; Lemieux, S.; Lamarche, B.; Laramee, C.; Corneau, L.; Lapointe, A.; Tessier-Grenier, M.; Robitaille, J. Development of a Web-Based 24-h Dietary Recall for a French-Canadian Population. Nutrients 2016, 8. [CrossRef] [PubMed]

16. Lafreniere, J.; Laramee, C.; Robitaille, J.; Lamarche, B.; Lemieux, S. Assessing the relative validity of a new, web-based, self-administered $24 \mathrm{~h}$ dietary recall in a French-Canadian population. Public Health Nutr. 2018, 21, 2744-2752. [CrossRef] [PubMed]

17. Savard, C.; Lemieux, S.; Lafreniere, J.; Laramee, C.; Robitaille, J.; Morisset, A.S. Validation of a self-administered web-based 24-hour dietary recall among pregnant women. BMC Pregnancy Childbirth 2018, 18, 112. [CrossRef] [PubMed]

18. Garriguet, D. Diet quality in Canada. Health Rep. 2009, 20, 41-52. [PubMed]

19. Kennedy, E.T.; Ohls, J.; Carlson, S.; Fleming, K. The Healthy Eating Index: Design and applications. J. Am. Diet. Assoc. 1995, 95, 1103-1108. [CrossRef]

20. Moran, L.J.; Sui, Z.; Cramp, C.S.; Dodd, J.M. A decrease in diet quality occurs during pregnancy in overweight and obese women which is maintained post-partum. Int. J. Obes. (Lond.) 2013, 37, 704-711. [CrossRef] [PubMed]

21. Shin, D.; Bianchi, L.; Chung, H.; Weatherspoon, L.; Song, W.O. Is gestational weight gain associated with diet quality during pregnancy? Matern. Child Health J. 2014, 18, 1433-1443. [CrossRef] [PubMed]

22. Tsigga, M.; Filis, V.; Hatzopoulou, K.; Kotzamanidis, C.; Grammatikopoulou, M.G. Healthy Eating Index during pregnancy according to pre-gravid and gravid weight status. Public Health Nutr. 2011, 14, 290-296. [CrossRef] [PubMed]

23. Eating Well with Canada's Food Guide; Health Canada: Ottawa, ON, Canada, 2007.

24. Health Canada. Licensed Natural Health Product Database. Available online: https://health-products. canada.ca/lnhpd-bdpsnh/index-eng.jsp (accessed on 1 May 2019). 
25. Chandonnet, N.; Saey, D.; Almeras, N.; Marc, I. French Pregnancy Physical Activity Questionnaire compared with an accelerometer cut point to classify physical activity among pregnant obese women. PLoS ONE 2012, 7, e38818. [CrossRef] [PubMed]

26. Chasan-Taber, L.; Schmidt, M.D.; Roberts, D.E.; Hosmer, D.; Markenson, G.; Freedson, P.S. Development and validation of a Pregnancy Physical Activity Questionnaire. Med. Sci. Sports Exerc. 2004, 36, 1750-1760. [CrossRef] [PubMed]

27. Craig, C.L.; Marshall, A.L.; Sjostrom, M.; Bauman, A.E.; Booth, M.L.; Ainsworth, B.E.; Pratt, M.; Ekelund, U.; Yngve, A.; Sallis, J.F.; et al. International physical activity questionnaire: 12-country reliability and validity. Med. Sci. Sports Exerc. 2003, 35, 1381-1395. [CrossRef] [PubMed]

28. Otten, J.J.; Hellwig, J.P.; Meyers, L.D. (Eds.) Dietary Reference Intakes: The Essential Guide to Nutrient Requirements; National Academies Press: Washington, DC, USA, 2006.

29. Institute of Medicine (US) Subcommittee on Interpretation and Uses of Dietary Reference Intakes; Institute of Medicine (US) Standing Committee on the Scientific Evaluation of Dietary Reference Intakes. Application of DRIs for Group Diet Assessment. In DRI Dietary Reference Intakes: Applications in Dietary Assessment; National Academies Press: Washington, DC, USA, 2000.

30. Talai Rad, N.; Ritterath, C.; Siegmund, T.; Wascher, C.; Siebert, G.; Henrich, W.; Buhling, K.J. Longitudinal analysis of changes in energy intake and macronutrient composition during pregnancy and 6 weeks post-partum. Arch. Gynecol. Obstet. 2011, 283, 185-190. [CrossRef] [PubMed]

31. Derbyshire, E.; Davies, G.J.; Costarelli, V.; Dettmar, P.W. Habitual micronutrient intake during and after pregnancy in Caucasian Londoners. Matern. Child Nutr. 2009, 5, 1-9. [CrossRef] [PubMed]

32. Horan, M.K.; McGowan, C.A.; Gibney, E.R.; Byrne, J.; Donnelly, J.M.; McAuliffe, F.M. Maternal Nutrition and Glycaemic Index during Pregnancy Impacts on Offspring Adiposity at 6 Months of Age-Analysis from the ROLO Randomised Controlled Trial. Nutrients 2016, 8. [CrossRef] [PubMed]

33. Lindsay, K.L.; Heneghan, C.; McNulty, B.; Brennan, L.; McAuliffe, F.M. Lifestyle and dietary habits of an obese pregnant cohort. Matern. Child Health J. 2015, 19, 25-32. [CrossRef] [PubMed]

34. Moran, L.J.; McNaughton, S.A.; Sui, Z.; Cramp, C.; Deussen, A.R.; Grivell, R.M.; Dodd, J.M. The characterisation of overweight and obese women who are under reporting energy intake during pregnancy. BMC Pregnancy Childbirth 2018, 18, 204. [CrossRef] [PubMed]

35. Brassard, D.; Laramee, C.; Corneau, L.; Begin, C.; Belanger, M.; Bouchard, L.; Couillard, C.; Desroches, S.; Houle, J.; Langlois, M.F.; et al. Poor Adherence to Dietary Guidelines among French-Speaking Adults in the Province of Quebec, Canada: The PREDISE Study. Can. J. Cardiol. 2018, 34, 1665-1673. [CrossRef]

36. Wilson, R.D.; Wilson, R.D.; Audibert, F.; Brock, J.A.; Carroll, J.; Cartier, L.; Gagnon, A.; Johnson, J.A.; Langlois, S.; Murphy-Kaulbeck, L.; et al. Pre-Conception Folic Acid and Multivitamin Supplementation for the Primary and Secondary Prevention of Neural Tube Defects and Other Folic Acid-Sensitive Congenital Anomalies. J. Obstet. Gynaecol. Can. 2015, 37, 534-552. [CrossRef]

37. Bassett-Gunter, R.L.; Levy-Milne, R.; Naylor, P.J.; Symons Downs, D.; Benoit, C.; Warburton, D.E.; Blanchard, C.M.; Rhodes, R.E. Oh baby! Motivation for healthy eating during parenthood transitions: A longitudinal examination with a theory of planned behavior perspective. Int. J. Behav. Nutr. Phys. Act. 2013, 10, 88. [CrossRef] [PubMed]

38. Hanson, M.A.; Bardsley, A.; De-Regil, L.M.; Moore, S.E.; Oken, E.; Poston, L.; Ma, R.C.; McAuliffe, F.M.; Maleta, K.; Purandare, C.N.; et al. The International Federation of Gynecology and Obstetrics (FIGO) recommendations on adolescent, preconception, and maternal nutrition: “Think Nutrition First". Int. J. Gynaecol. Obstet. 2015, 131 (Suppl. 4), S213-S253. [CrossRef]

(C) 2019 by the authors. Licensee MDPI, Basel, Switzerland. This article is an open access article distributed under the terms and conditions of the Creative Commons Attribution (CC BY) license (http://creativecommons.org/licenses/by/4.0/). 